VIEWPOINT

\title{
Will Africa be Devastated by Covid-19 as Many Predicted? Perspective and Prospective
}

\author{
Yifru Berhan*
}

To esteemed readers: This article was originally published on The Ethiopian Herald (Newspaper) on $24^{\text {th }}$ of April, 2020. Permission for any publication was granted by The Ethiopian Herald editorial office.

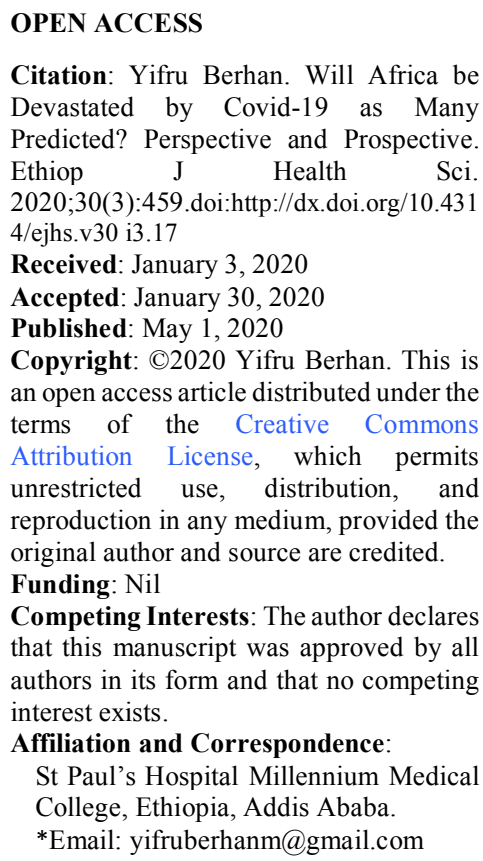

Citation: Yifru Berhan. Will Africa be Devastated by Covid-19 as Many Predicted? Perspective and Prospective. Ethiop $\mathrm{J}$ Health Sci. 2020;30(3):459.doi:http://dx.doi.org/10.431 4/ejhs.v30 i3.17

Received: January 3, 2020

Accepted: January 30, 2020

Published: May 1, 2020

Copyright: (C2020 Yifru Berhan. This is an open access article distributed under the terms of the Creative Commons Attribution License, which permits unrestricted use, distribution, and reproduction in any medium, provided the original author and source are credited.

Funding: Nil

Competing Interests: The author declares that this manuscript was approved by all authors in its form and that no competing interest exists.

Affiliation and Correspondence: St Paul's Hospital Millennium Medical College, Ethiopia, Addis Ababa.

*Email: yifruberhanm@gmail.com

\section{INTRODUCTION}

Since the novel coronavirus disease 2019 (Covid-19 or SARS CoV-2 infection) has been declared as pandemic, several mathematicians and statisticians have developed different trajectory curves for Africa, with the assumption that the virus can have an exponential pattern of transmission. According to Economic Commission for Africa, 300k3.3 million COVID-19 related deaths may occur in Africa (1). A large body of literature and international media have also predicted that Africa is going to be flooded, much higher than Europe and the United States of America (USA). For Ethiopia alone, some estimated 28-33 million with full mitigation and 70-107 million people without mitigation actions can get infected. When the author of this perspective sees such an easy to do, but hard to conceive figures, he likes to join the closed loop forum and express what his thought is.

As of $21^{\text {st }}$ April 2020, close to 23k confirmed cases and 1000+ deaths are reported from 55 African countries, while the global figure climbs to more than two and a half million and individual countries in the West are reporting the highest ever cases $(200 \mathrm{k}-700 \mathrm{k}+)$ and deaths $(24 \mathrm{k}-42 \mathrm{k}+)$ in less than three months (2). The hardest hit countries being the most capable to tackle such kind of infectious outbreak, and the extremely contagious nature of this virus is the puzzle and unprecedented phenomenon.

Virtually, countries of the globe do not look like they are ordered by the burden of this infection; the actual magnitude of case and death load in each looks as if they are ordered by their economic power and financial muscle. The bottom line is that this infection has been exponentially spreading, and becoming highly prevalent and fatal in the richest countries. That is not yet happening in countries within the tropical climate zone. Will it be like that in the weeks or months to come is the core question of this perspective.

Some may argue that the developed countries testing capacity is what has inflated the case load, citing USA and Germany as an example. Yes, the high test uptake has helped the developed countries to identify as many cases as possible in a short period of time. However, the testing capacity alone could not explain the whole picture of the reality on the ground. What has been disproportionately

DOI: http://dx.doi.org/10.4314/ejhs.v30i3.17 
rising in the last three months in the Western countries of the temperate climate zone was not only case load, but also the staggering mortality figure and the severely morbid cases (hospitalization for pneumonia, ICU care, dialysis, and blood transfusion), which are the two key measurements to show how severe the actual magnitude of the Covid19 is.

A very important argument is; had the Covid19 transmission been as contagious as in Europe and USA, by this time, every health facility in Africa and other tropical countries could have been flooded with severely ill patients and deaths. But, that is not the case in any of African and tropical countries. The other side of the coin is; the overwhelming cases and deaths experienced in Europe and USA is despite the fact that they started to report Covid-19 confirmed cases almost same time or later than many of the countries in the tropical climate zone.

Up to now, the proportion of mortality in the majority of Covid-19 reporting countries is in the lower range $(<10 \%)(2)$. The relatively high case fatality rates among countries with larger case load are reported from Europe and one North African country (Algeria). This observation may lead to pose questions on the predilection of the transmission and the survival of the virus particle outside the human body at different climate zone, as discussed below. On blanket view of the global distribution of the infection, relatively low case and death load is observed across Africa, South Middle East, South and Southeast Asia and Latin America. Since the beginning, the epicenter has moved from East to West along the temperate climate zone, and causes incomparably massive casualties.

Even in Africa, the relatively hardest hit countries are still outside the tropical zone (Algeria, Egypt, Morocco and South Africa). Countries in the tropical zone of Asia and Latin America, with relatively high case load, are not yet as hot spot as Western countries in the temperate zone, despite the proportional duration of exposure; the cumulative number of deaths is incomparably low. The mathematical modeling result for the stated period using hypothetical numbers and the reported data from several tropical countries is far apart. Brazil looks an exception, probably due to the rainy season or high tourist flow just around the outbreak.
Further, this is despite the fact that some African countries has started reporting Covid-19 cases even earlier than some Western countries with high case load. Many authors have underscored the high mobility of the global population for the rapid spread of Covid-19 in hot spot areas. But, the number of cases in many of the African countries is large enough to result in exponential transmission of the virus and be able to make hot spot. Age and sex strata are some of the factors determining the prognosis, but not that much strong to justify the exponential transmission. Hereunder, some more critical appraisal is presented.

\section{What can we learn from history to upkeep the above argument?}

With our limited knowledge, what history tells us may be in line with what we are observing the Covid-19 pandemic at this juncture. As read from chronicles of influenza and other coronaviruses pandemics, the biology of SARS Cov-2 may have something to do with the climate to have exponential or restricted rate of transmission.

It is not debatable that SARS Cov-2 is the seventh well known new coronavirus that infects humans (after SARS-CoV, MERS-CoV, HKU1, NL63, OC43 and 229E) (3). SARS-CoV and MERS-CoV are also new coronaviruses detected in humans in 2002 and 2012, respectively, and are highly fatal (4). The mean global case fatality rates of SARS CoV-2, SARS CoV and MERS CoV are $5 \%, 10 \%$ and $35 \%$, respectively $(2,4)$. The last four coronaviruses usually cause mild upper respiratory tract infection, with the exception of OC43, which once had caused an outbreak of severe pneumonia in France (5).

Like SARS CoV-2, SARS CoV originated in China (Guandong province), and was subsequently able to disseminate to Europe and America, almost similar with the current trend. SARS $\mathrm{CoV}$ has become pandemic by reaching to 33 countries in different continents, while the epicenter was in Hong Kong, with a total 8,096 infections and 774 fatalities in a year period globally (4). Asian and European countries are the ones which are still sporadically reporting SARS CoV infection. The dissemination of SARS CoV to countries in the tropical zone along the globe, however, was minimal or none at all.

DOI: http://dx.doi.org/10.4314/ejhs.v30i3.16 
Another important milestone that consolidates the origin of the previous and current SARS is the emergence of another new coronavirus in 2016 (named SADS CoV) from China near the origin of SARS CoV, which killed 25k piglets (6). The point is; the spread of MERS CoV and SARS CoV was predominantly in Asia and Europe.

Probing the history of influenza pandemics and the tropical epidemics can also give some clue on the likelihood distribution and proportion of cases and deaths of the current pandemic. Since the time of Hippocrates (460-377 BC), infectious disease pandemics had ravaged millions of human lives. Some of the attributed etiologies for the outbreaks had international and regional propensity. Yersinia pestis, which caused the 'black death' of 75-200 million people and the typhus fever which killed more than 3 million in Europe alone during the second world war are bacterial etiology, and were not having continental or national boundary. Neisseria meningitides (the one causing meningitis outbreak along the meningitis belt), malaria, yellow fever, cholera, shigellosis, dengue fever are still common causes of outbreaks in the tropical climate zone. Seasonal influenza outbreaks due to H3N2, $\mathrm{H} 2 \mathrm{~N} 2$ and $\mathrm{H} 1 \mathrm{~N} 1$ have been predominantly occurring in the Northern hemisphere.

The implication is that geographical and climate change may influence the microorganisms' survival outside the human body, and may determine the incubation period of the pathogen in the human body. Influenza outbreaks occurred in Europe and USA during cold and low humid weather (usually starting in winter and subsiding in spring), while meningitis and cholera outbreaks occurred in the tropics during hot weather and rainy season (usually preceding flood), respectively.

Although there is a long list of highly catastrophic influenza pandemics at different period of human history, it is worth mentioning those in the late $19^{\text {th }}$, early and second half of the $20^{\text {th }}$ century and early in this century. Among others, like the current pandemic, the 'Russian flu'/H3N2 (18891890) and 'Hong Kong flu' pandemics/H3N2 (1968-1970) which each killed one to four million people, and 'Asian flu' pandemic/H2N2 (19571958) which killed 2 million people originated from Asia and massively spread to Europe and America.
'Spanish flu'/H1N1 (1918-1920), which originated from Spain, and killed 25-50 million people spread globally. Another 'Russian flu' pandemic/H1N1 erupted in 1977-1978 and killed around 700k people worldwide (7).

An important observation was that, like the currently observed Covid-19 pandemic, the morbidity and mortality of the aforementioned influenza outbreaks were not that much spreading and killing outside the temperate zone, at least in Africa. The first 'Russian flu', for instance, reached in Northern African countries, including Egypt and Algeria, but the case load and mortality were not as high as the European countries. In England alone, more than 132,000 people died of 'Russian flu' in just one year. The 'Asian flu' pandemic had also reached to many parts of Africa, but was not highly catastrophic as it was in the Northern hemisphere. The Spanish flu was a bit exceptionally highly fatal in many parts of the world. It was estimated that about 2\% of Africans died. Even then, in South Africa (temperate zone) the estimated mortality (500k) was 10-fold higher than Ethiopia (40k-50k), which is somehow in line with the current pandemic (8).

As a continuation of the old pandemics, the seasonal outbreaks and casualties of influenza in Europe and USA are still devastating. According to the Centers for Disease Control and Prevention (CDC) of USA report, the 2017-2018 influenza outbreak killed $61 \mathrm{k}$ people in the USA alone, which was higher than the influenza related deaths (56k) in 2012-2013 season (9). The 2017 global estimate of deaths due to seasonal influenza was between 291k646k (10). Most of these deaths due to seasonal influenza occur in North Asia, Europe and North America.

The 2009 swine flu pandemic that originated from Mexico was the third H1N1 influenza pandemic (2009-2010) that resulted in about 150k$575 \mathrm{k}$ fatalities predominantly in North and South America, West Europe, South and Southeast Asia, and Australia (11). Interestingly, among African countries, only Egypt, Algeria and South Africa were part of the swine flu pandemic. The WHO annual estimate of mortality due to seasonal influenza is also a quarter to half a million. The bottom line is that, with the exception of the Spanish

DOI: http://dx.doi.org/10.4314/ejhs.v30i3.17 
flu, neither of the influenza pandemics seriously affected the African continent.

The purpose of citing the above mortality figures is to show that there are infectious disease conditions which follow seasonal changes and are not proportionally distributed across the globe. The common causes of infectious outbreaks in the tropics and temperate zone are not same. Otherwise, the influenza viruses and coronaviruses are biologically, pathogenically and epidemiologically completely different. What is probably in-common in the two groups is their potential to cause pneumonia and ability to expose to secondary bacterial infection.

\section{Comparative rate of increment by cases and deaths}

From previous coronavirus outbreaks (SARS CoV, MERS CoV) and influenza outbreaks as a proxy, one may extrapolate that the tropical zone may not be hit by Covid-19 as hard as the temperate zone. The explosive nature of the Covid-19 spread to every corner of the six continents, however, may make it incomparable in all parameters with the previous coronavirus and influenza outbreaks. Notwithstanding this thought, the already observed rate of spread in the tropics is not as skyrocketing as the temperate zone, despite the virus lands almost two months back in many countries. In other words, the cases and deaths will likely increase, but not with flooding nature as seen in the temperate zone.

As noted earlier, the number of confirmed cases may be underestimated due to lack of adequate testing. However, the seriously ill and death rates cannot be underestimated. Let alone the Covid-19like outbreak, we know how many hospitals are overwhelmed when there is an outbreak of smaller scale. Therefore, the severe morbidity and mortality indicators so far reported in the two zones have shown a remarkable disparity. Overall, the cumulative cases and deaths will as well increase in Africa, and it may even last longer than other types of pandemics, but the chance of exponential increment looks less likely. As SARS CoV, Covid19 is likely to be endemic in Asia, Europe and North America.
Additional factors why Africa and many other tropical countries are likely to have a very slow spread of the Covid-19

Among others, the very crowded day and night social life and the poor personal and environmental hygiene in this zone can be thought as creating a very conducive environment for the spread of Covid-19 and any other communicable diseases. The high prevalence of malnutrition, malaria, tuberculosis, stress and non-communicable diseases (including diabetes and hypertension) may also make the majority of the people at higher risk for death. It is probably with this background why many are predicting the worst in Africa.

There is also a different assumption that the majority of African people and many more in the tropics are already exposed to several viral and bacterial infections (the justification for the planned BCG trial), which could help them to have a herd immunity to be protected from closely related pathogens. However, this theory may not be that much valid as the observed case fatality rate among Covid-19 infected persons is not different from other parts of the world.

If that is not the case, why the European or the American type of cases flooding into hospitals and overwhelming deaths are not yet observed in Africa, in particular, and other countries in the tropics? One may argue that the carriers of this virus are still few in the respective countries. As the international travel of the people in the region is relatively limited, yes, that is partly true. However, it is also hard to accept that many of the first carriers of the virus in Asia, Europe and USA had a chance to travel to China/Wuhan and around; quite significant number of community transmission was noted in Europe and USA. It is also not wise to think that the number of the first carriers of this virus was too few to transmit the virus in Africa as the transmission is presumed to have an exponential pattern ( 1 for 3 , then 3 for 9, 9 for 27 and the like).

Nigeria (the first most densely populated African country with highly mobile urban population) reported the first case on February $27^{\text {th }}$, but its case load and deaths after nearly two months are 665 and 22, respectively (2). The second most densely populated African country and owner of the famous Ethiopian airlines (Ethiopia), which has been flying to 130 international destinations till

DOI: http://dx.doi.org/10.4314/ejhs.v30i3.16 
March $20^{\text {th }} / 2020$ at which time restriction was made to 30 countries, has reported its first case about five weeks back; so far, has 114 cases and 3 deaths. Egypt (the third most densely populated African country with large tourist flow before the outbreak and large number of its citizens working in Europe) reported the first case one week earlier than Italy, but the magnitude of cases and deaths are totally incomparable (Italy's deaths are nearly 100 times of Egypt).

The case load curves of many African countries are also waxing and waning type; a steady type of increment is not yet observed in the last 2-3 months, which is against with an exponential spread. This may not be solely explained by the preventive measures implemented, as there were several inconsistencies and breaches in many parts of Africa.

Some also argue that the absence of community transmission is what has contributed to the low case load in Africa and elsewhere with few cases. It is true that the majority of the transmissions occur in the community in Europe and USA. However, it is still difficult to take it as a major reason for the low case load in several countries after reporting their respective first case nearly two months back, and with limited containing and mitigating actions.

If we take Ethiopia as an example, the wisdom of the author is that the Covid-19 was imported probably several weeks before the quarantine was initiated for those who were coming from abroad. Ethiopian airlines have been flying to more than 75 countries in the world (including China at 5 destinations). Therefore, as the very recently confirmed case reports showed, the assumption is that the virus carriers are already within the community, and probably in many other African countries too. The recently reported eight cases in Ethiopia came from the community with no contact history. The majority $(>60 \%)$ of the reported cases had an incubation period for more than two weeks, which is in contrast to the experience in the temperate zone. In literature, with few exceptions (24-27 days), the incubation period is less than two weeks. This is probably another research area on the impact of the climate on the multiplication of the virus in the human body and its survival outside the human body.
Although it is too early to deduce, the author's assumption is that Africa and many of other countries in the tropical zone are less vulnerable to coronavirus and influenza virus infections, primarily because of the weather condition. Until proved otherwise, this is probably because of the lower survival of the coronaviruses and influenza viruses in the external environment here in the tropics, whereby the humid weather condition is probably hostile to the virus to live outside the human body, thereby having a limited chance of proliferation and transmission from one person to another one unless it gets access as early as possible it is out.

This hypothesis is going to be tested soon, at least for SARS CoV-2. In 2011, Chan and colleagues reported that SARS CoV viability was rapidly lost $(>3 \log 10)$ at higher temperatures and higher relative humidity (12). Thus, in Europe, USA and north Asia, in particular, SARS CoV and SARS CoV-2 may live longer in the cold seasons outside the human body and be able to proliferate fast in the human body and infect as many people as possible. Furthermore, in Europe, SARS CoV-2 is reported as staying viable up to 17-day outside the human body. Had this been the case here in Africa and other places in the tropics, by this time, the Covid-19 related admissions to hospital and deaths could have been overwhelming.

With this regard, Ethiopia and many African countries may as well benefit from ultraviolet radiation (UVR) B exposure. It is well proven fact that ozone depletion, prolonged sunlight exposure, higher altitude and latitude increase the UVR B exposure, of which Ethiopia specifically has double advantage to be protected from Covid-19 like epidemics (high altitude and prolonged sun light exposure). Living organisms in general and microorganisms in particular are at higher risk for UVR B effect. UVR B is known to kill viruses by chemically modifying their genetic material (DNA and RNA viruses). During rainy or cloudy season, $70 \%-90 \%$ of UVR B type is blocked, which may be one of the possible reasons for low incidence of Covid-19 in the African region at this dry moment $(13,14)$.

Although it is unlikely to be the reason for all, one cannot ignore the timely actions of many of the

DOI: http://dx.doi.org/10.4314/ejhs.v30i3.17 
African governments' role in implementing many of the preventive measures, including lockdown in a few countries. In many places, the public response to the call was also appreciable. Here in the Ethiopian capital, contact tracing, handwashing and preparations with available resource for the worst ahead are very impressive and commendable. Streets are not that much crowded with pedestrians, and traffic jams have significantly decreased, which all have probably played some role in reducing the exposure. Here and there handwashing service and practice was looking as the campaign is active, but could not be long-lasting in many places.

What is likely to happen next? In the author's opinion, the case load is very likely to keep on increasing in all parts of Africa with a bit higher than the current pace; particularly, if the complacence of the people grows along with the slow increment of the cases and the deaths, the risk of transmission of this virus may be a bit higher than the current trend. Whatever the risk of transmission is, the cumulative figure is very unlikely to be in several millions as many predicted.

The argument is that since the majority of the African population lives in scattered rural area, with the current awareness and the weather condition as described above, the risk of a large area spread in short a while is less likely. The expectation is that, before the spread of this virus reaches a larger scale, the two-three waves of the outbreak will be over. Then after, sporadic cases will keep on emerging until the season is favorable for the virus's spread. Similar spread and trend is expected in the majority of tropical countries as learnt from the previous pandemics.

If that is not the case, this virus will not have a pattern similar to other infectious outbreaks (ascending, flattening and descending pattern). If the latter is true, Africa will not be an exception; years long outbreak can occur elsewhere and the destiny will be unpredictable. The experience in the last three months, however, has shown that Covid-19 outbreak is almost similar with previous pandemics; some countries like China and South Korea are already entertaining the second wave after coming from apex to close to the baseline.

Therefore, the first scenario is; like many of other viral infections, those infected with Covid-19 will develop humoral immunity and be protected from reinfection. As the majority of the population becomes immune (herd immunity) in due course, the chance of outbreak and the incidence rate will be less and less. The coming generation as well will be exposed in their earlier age and similarly develop the herd immunity. The possibility of developing a vaccine is within the domain of this assumption.

The second scenario is reinfection. Naturally, the majority of viral infections do not recur (with exception of those integrating their genome to the human genome, like HIV, Human papilloma virus). Covid-19 antigen, however, may not stimulate the human immune system to develop antibody against reinfection. This is much worrying as it may herald the difficulty to develop vaccine. Researchers are soon to rule in or rule out whether the first or the second scenario is true. Anecdotal evidence from China and South Korea shows the possibility of reinfection, but that needs to be verified whether it is reinfection, reactivation or false positive result of the earlier test.

\section{Still commendable actions:}

African government and health stakeholders should not develop complacence with the slow rate of increment or reduction from recorded apex. Apart from the seasonal nature, the character of infectious outbreaks is having two-three waves of mass infection; the latter waves are usually severe, for which complacence takes the major share. As the rainy and cold seasons are coming along the equator, second and third waves may be harder than before. Seriously ill patients in hundreds to thousands are not manageable in an African setting.

Therefore, the already in action preventive interventions have to be maintained or strengthened till this outbreak is declared over (particularly contact tracing, avoiding or minimizing physical contact, hand washing, social distancing and universal mask use when exposure to other persons or patients is inevitable).

The lockdown for Africa, in particular, is a very controversial and challenging action. The author's opinion is that, as far as the social distancing and other preventive actions are in place, the lockdown action is not a wise decision for Africa. The living style in the village and at the household level is already congested type; it is not uncommon to find dozens of people living and sleeping in a room. If

DOI: http://dx.doi.org/10.4314/ejhs.v30i3.16 
lockdown is implemented, it should be complemented by mass testing, which is not economically and technically feasible for Africa. Therefore, phase by phase, the workforce has to resume the daily activities with stringent application of physical distancing and universal mask use. Then after, students may be allowed to attend class on shift base (may be odd/even number on a day) with good advice and in-school close monitoring of the physical distancing.

Otherwise, the economic and social devastating effect of this virus to the African continent in general and poor countries in particular may not be tolerable and easily reversible. It may even result in social unrest and political crisis. Therefore, we should not further delay the resumption of economically rate limiting sectors. If things go significantly in the wrong direction, preventive actions can be retightened as many countries are doing.

\section{Covid-19 is a 'yellow flag' for African governments in the tropical zone:}

In the author's opinion, whatever the consequence of this pandemic is in Africa or elsewhere, it is another turning point in human history after the Spanish flu and the second world War, by bringing about an extraordinary change in the political, economic and social landscape across the globe. From social interaction, international connectedness and travel perspective, I do not think that I am wrong if I say that Covid-19 has dramatically changed the so called "world is a village" to "world is an individual'. The economic crisis described by many, as the deep recession looming, may also hit hard Africa and other low income countries with fragile economy.

Beyond controlling the outbreak, the big lesson for the world is to get ahead better prepared to manage such scale of outbreaks, and to make a significant paradigm shift in resourcing future researches to prevent and treat infectious outbreaks. For decades, communicable diseases are left to low income countries (particularly to Sub Saharan Africa) with limited effort to develop vaccines and antimicrobials in resource rich countries. In short, the lesson acquired from Covid-19 pandemic is expected to be the legacy for the generation to come.
Specific to Africa, it is not arguable that Covid19 is a practical test that has clearly shown how much the health facilities are scarce and ill-equipped to handle such scale of public health emergency. When nations in Africa are aware of that the expected Covid-19 caseload is projected to be in several hundred thousand at a time, they also realized that available hospital beds in each big town are only a few hundred or less. Similarly, the available health facilities and the health force to provide intensive care to critically ill patients are either non-existent or rudimentary. It is ahead a very disturbing experience for many of them.

As an example of status indicator, the two countries with large population size (Nigeria and Ethiopia) are each able to test $<10,000$ individuals in nearly two months. Some African countries reported zero, 3, 70 and the like number of ventilators at the national level while the demand is in thousands. This is in contrast to the first and second world where the testing and the basic life support capacity is extraordinary. In one of his briefings, his excellency Andrew Cuomo, the New York State governor requested the Federal Government to supply $30 \mathrm{k}$ ventilators while he has $11 \mathrm{k}$ at hand. The author is not sure whether the 54 nations in Africa in total have this number of ventilators.

It is, therefore, Covid-19 is a learning curve for African governments in the tropical zone to revise their health policy and get better prepared for similar or larger outbreaks in the years to come. Covid-19 is not only a deep wake up click, but also a great 'opportunity' to mobilize the human force and financial resource to catch up in a short period of time with affordable cost.

Around two decades back (2001), African leaders signed the Abuja Declaration, which was stated as African countries should allocate $15 \%$ of their annual budget for health services (15). In practice, however, the majority could not make it even $3 \%$. That is why the health system and health facilities in Africa remained crippled despite the staggering case load in every referral hospital. As a result, African countries are enforced to export the financially capable patients (including leaders) to middle east and Asia with a yearly increasing

DOI: http://dx.doi.org/10.4314/ejhs.v30i3.17 
number that has exploited the country's scarce resource.

In the era of Covid-19, however, no way, nowhere to go. This is another reality, what makes Covid-19 a breathtaking phenomenon. Neither the economic nor the military power enables the abler to escape this invisible disease by traveling somewhere else. Invariably, the Covid-19 victim or susceptible individuals worldwide are getting help only from the nearby hospitals.

Luckily, the hospitals and treatment centers in these poor countries are not yet overwhelmed by Covid-19 cases. If the worst comes (cases flooding like the Europe and USA), there is an extremely low chance of getting medical care in Africa. Whether we like it or not, it will be a natural death and survival ('survival of the fittest'), like in the time of the old pandemics. African VIPs and well to do's will not be an exception. It is from this bad experience, what African leaders and every one of us need to take a big lesson to get prepared ahead for the worst to come (taking Covid-19 as 'a blessing in disguise').

In general, Covid-19 is another 'red flag' for humankind. In other words, the recent 'red flag' for humankind is the emergence of four highly fatal coronavirus strains (SARS $\mathrm{CoV}$, MERS $\mathrm{CoV}$, SADS CoV and now SARS CoV-2) in less than two decades with extremely fast global dissemination of SARS CoV-2 in three months and the lack of treatment or vaccine for either. Related to this, the sporadically exploding highly fatal viral hemorrhagic fevers in the tropical zone (like Ebola and Marburg viruses) with on and off migration to other countries and again with no treatment or vaccine are a previously well noted 'red flag' for humankind.

Above all, the emergence of four new coronaviruses as a human pathogen in the first quarter of the $21^{\text {st }}$ century is a 'red flag' for the emergence of another new coronavirus in the years to come, whose effect and destiny cannot be predicted. Could the climate change have an influence in the mutation of these new coronaviruses and probably many more is not yet well substantiated. Overall, the earlier appearance of the third generation of diseases implies that the human battle with the emerging viruses and bacteria will be tougher than before.
Acronyms:

SARS $=$ Severe acute respiratory syndrome

MERS $=$ Middle east respiratory syndrome

SADS $=$ Swine acute diarrhea syndrome

\section{REFERENCES}

1. Economic Commission for Africa. Addis Ababa, Ethiopia. Covid-19 in Africa:

Protecting lives and economies. 2020.

Accessed on April 20 ${ }^{\text {th }}, 2020$ from: http//: www. npr.org/sections/coronavirus

2. Worldometer. Accessed on April $20^{\text {th }}, 2020$ from: worldometer.info/coronavirus.

3. Zhu N, Zhang D, Wang W, Li X, Yang B, Song $J$. et al. A novel coronavirus from patients with pneumonia in China, 2019; N Engl J Med, 2020; (382)727-733.

4. Cortellis. A Clarivate Analytics Solution. Diseases briefing: Coronaviruses. 2020. Accessed on April 20 ${ }^{\text {th }}, 2020$ from: https://clarivate.com/wpcontent/uploads/dlm_u ploads/2020/01/CORONAVIRUS-REPORT3.6.2020_v1.pdf

5. Vabret A, Mourez T, Gouarin S, Petitjean J, Freymuth F. An Outbreak of Coronavirus OC43 Respiratory Infection in Normandy, France. Clin Infect Dis, 2003; 36(8):985-9.

6. Zhou P, Fan H, Lan T, Yang X-L, Shi W-F, Zhang W, et al. Fatal swine acute diarrhoea syndrome caused by an HKU2-related coronavirus of bat origin. Nature, 2018, 556(7700): 255.

7. Saunders-Hastings PR, Krewski D. Reviewing the History of Pandemic Influenza: Understanding Patterns OF Emergence and Transmission. Pathogens, 2016; 5(4): 66.

8. Yayehyirad Kitaw Y, Kaba M. A century after Yehidar-beshita [The Spanish flu in Ethiopia]: Are we prepared for the next pandemic? Eth J Health Dev, 2018; 32(1):59-62

9. Centers for Diseases Control and Prevention. 2017-2018 Estimated Influenza Illnesses, Medical visits, Hospitalizations, and Deaths and Estimated Influenza Illnesses, Medical visits, Hospitalizations, and Deaths Averted by Vaccination in the United States. Accessed on April $21^{\text {st }}, \quad 2020$ from: 
https://www.cdc.gov/flu/about/burdenaverted/2017-2018.htm

10. luliano AD, Roguski KM, Chang HH, Muscatello DJ, Palekar R, Tempia S. Estimates of Global Seasonal InfluenzaAssociated Respiratory Mortality: A Modelling Study. Lancet, 2018; 391(10127):1285-1300.

11. Noh JY, Kim WJ. Influenza vaccines: ummet needs and recent developments. Journal of Infection and Chemotherapy, 2013: 45:375-6.

12. Chan KH, MalikPeiris JS, Lam SY, Poon LLM, Yuen KY, Seto WH. The Effects of Temperature and Relative Humidity on the Viability of the SARS Coronavirus. Advances in Virology, 2011; ID 734690. doi: $10.1155 / 2011 / 734690$

13. NASA. Ultraviolet radiation: how it affects life on Earth. Accessed on April 21st, 2020 from: https://earthobservatory.nasa.gov/features/UV B/uvb_radiation3.php.

14. ZIDBITS. On Cloudy Days, Are UV Rays Stronger? Accessed on April 21st, 2020 from: https://zidbits.com/2011/04/on-cloudy-daysare-uv-rays-stronger/

15. Heads of State and Government of the Organisation of African Unity (OAU). Abuja Declaration on HIV/AIDS, Tuberculosis and other related infectious diseases. Abuja, Nigeria, 2001. Accessed on April 21st, 2020 from:

https://au.int/sites/default/files/pages/32894file-2001-abuja-declaration.pdf 